\title{
Severe transient left ventricular dysfunction induced by thyrotoxicosis
}

\author{
E. Bird-Lake
}

Published online: 3 May 2011

(C) The Author(s) 2011. This article is published with open access at Springerlink.com

\begin{abstract}
We report on a 44-year-old woman presenting with chest pain and dyspnoea without previous stress-related events. By means of echocardiography severe left ventricular dysfunction and wall motion abnormalities resembling stressinduced cardiomyopathy (Tako Tsubo) were seen. Laboratory investigation revealed thyrotoxicosis and elevated cardiac markers. Six days after starting medical treatment, complete restoration of the left ventricular function was observed. The transient left ventricular dysfunction was induced by thyrotoxicosis resembling stress-induced cardiomyopathy that resolved completely after medical treatment.
\end{abstract}

Keywords Thyrotoxicosis $\cdot$ Stress-induced Cardiomyopathy $\cdot$ Left ventricular dysfunction

Thyroid dysfunction has a direct and indirect effect on the cardiovascular system. Biologically active thyroid hormone T3 affects cardiac contractility, heart rate, diastolic function, and systemic vascular resistance. In hyperthyroidism, cardiac chronotropy, inotropy and cardiac output are increased [1]. Walker et al. [2] demonstrated that T3 enhances contractility through adrenergic stimulation. Stress-induced cardiomyopathy is based on surges of

\footnotetext{
E. Bird-Lake

Nilda Pintostraat \#29,

1103 MK Amsterdam, the Netherlands

E. Bird-Lake $(\bowtie)$

Koningin Julianaplein 58,

1502 DV Zaandam, the Netherlands

e-mail: bird.e@zaansmc.nl

E. Bird-Lake

e-mail: ebirdlake@hotmail.com

catecholamine levels released by emotional or physical stress resulting in myocardial stunning [3]. Excessive T3 and catecholamine can result in an impaired left ventricular function. Treatment of thyrotoxicosis and decreasing catecholamine similarly results in restoration of the left ventricular function within days to months after initiating treatment.

\section{Case report}

A 44-year-old woman presented to the emergency room with shortness of breath and thoracic pain radiating to the left arm and shoulder. She had exercised earlier without any complaints. Several hours before presentation the symptoms had progressed. For several months she had been having palpitations and was feeling agitated and perspiring excessively. Previous medical history revealed a left prosthetic hip replacement. She was not on any medication prior to admission.

Upon examination her vital signs showed a blood pressure of $158 / 102 \mathrm{mmHg}$, a pulse rate of 135 beats $/ \mathrm{min}$, a normal temperature and oxygen saturation of $100 \%$ on room air and no signs of heart failure. Laboratory research revealed an elevated troponin $\mathrm{T}$ of $0.18 \mu \mathrm{G} / \mathrm{l}$, a creatinine kinase of $170 \mathrm{U} / 1$ and CK-MB of $17.9 \mu \mathrm{G} / \mathrm{l}$. Leucocytes and $\mathrm{C}$-reactive protein were elevated. Electrocardiography revealed elevation of the ST segment in V2. An echocardiogram documented severe left ventricular systolic dysfunction with wall motion abnormalities. The diagnosis was stressinduced cardiomyopathy (Tako Tsubo) or perimyocarditis. Non-significant coronary abnormalities were found by coronary angiogram. Left ventriculogram showed akinetic wall motion abnormality in posterolateral and diaphragmatic wall 
Fig. 1 Left ventriculogram with wall motion abnormalities in the distal segments and normal wall motion in basal segments comparative to stress-induced cardiomyopathy. a Systolic phase, b Diastolic phase

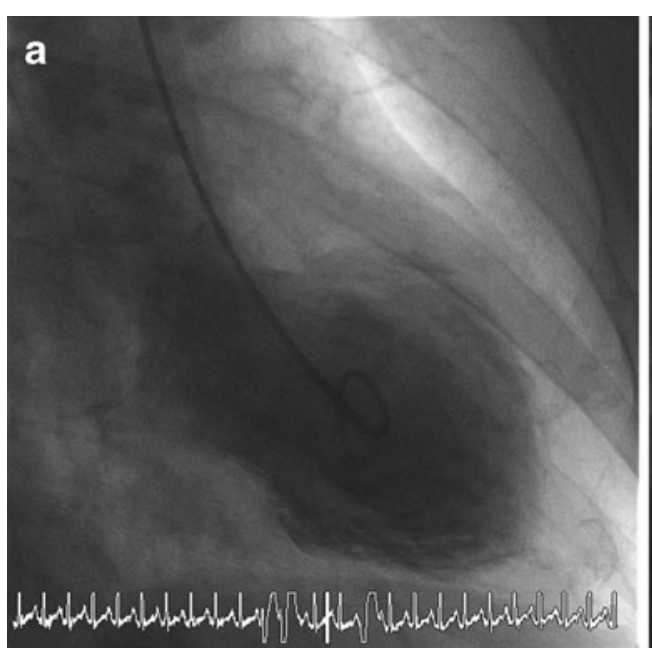

segments, and a hypokinetic apex (Fig. 1). Medical treatment with furosemide, anticoagulants and an ACE inhibitor was started. On the ECG, negative T waves evolved combined with prolonged QT duration (Fig. 2).

The patient appeared to have had a previous incidence of thyrotoxicosis (Graves disease) in 2002. Her current thyroid function confirmed a toxic state with a thyroid-stimulating hormone (TSH) of $<0.05 \mathrm{mU} / 1$ and free thyroxin (T4) of $>100 \mathrm{pmol} / \mathrm{l}$ and tri-iodothyronine (T3) of $26 \mathrm{pmol} / \mathrm{l}$. Six days after treatment with propylthiouracil and propanolol, her heart rate reduced to 80 beats/min and the sequential echocardiogram showed an improvement of her systolic left ventricular function (Fig. 3). Magnetic resonance imaging measured a left ventricular ejection fraction of $52 \%$. There was mild concentric left ventricular hypertrophy and no signs of myocardial necrosis.

a

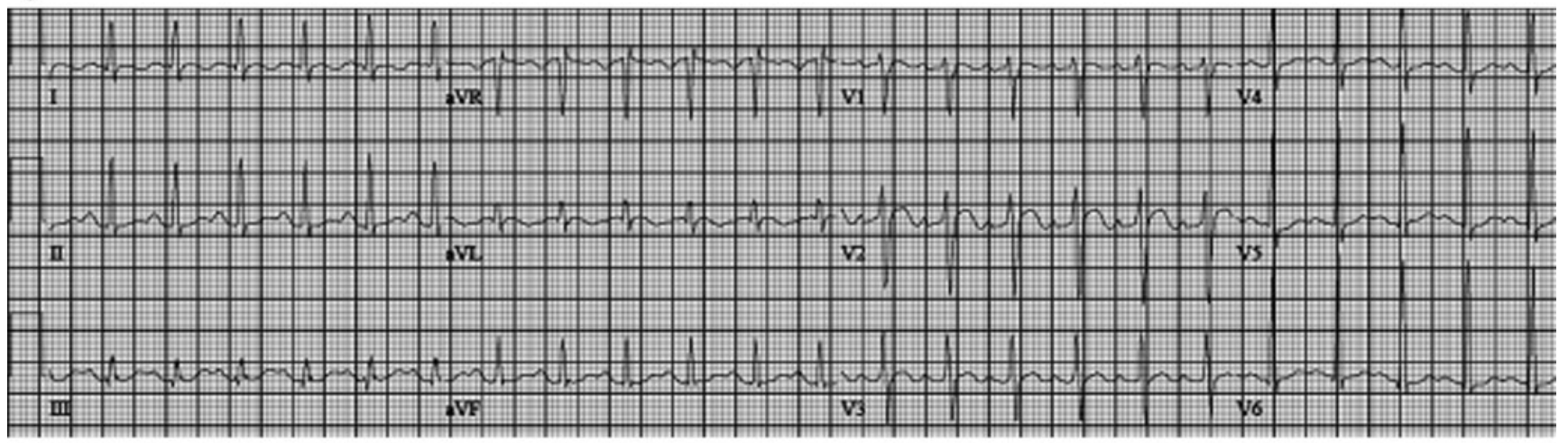

b

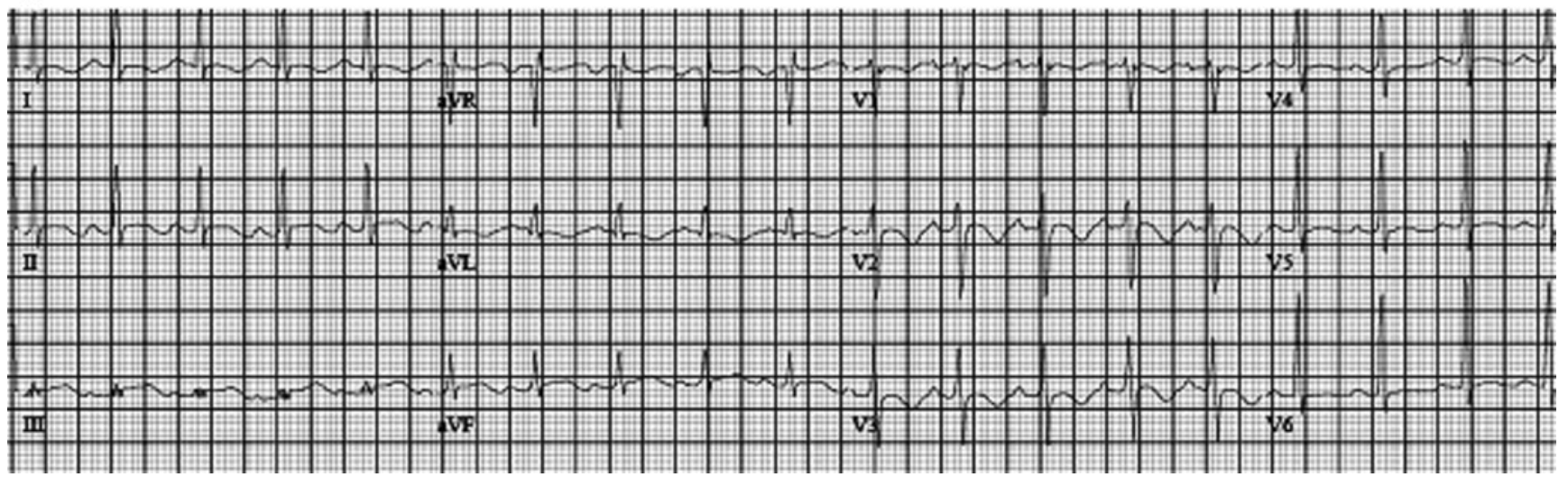

Fig. 2 ECG at admission (a) with slight ST elevation in V2 and $16 \mathrm{~h}$ after admission (b) with negative T waves in the right precordial leads, I and aVL with prolonged QT duration 


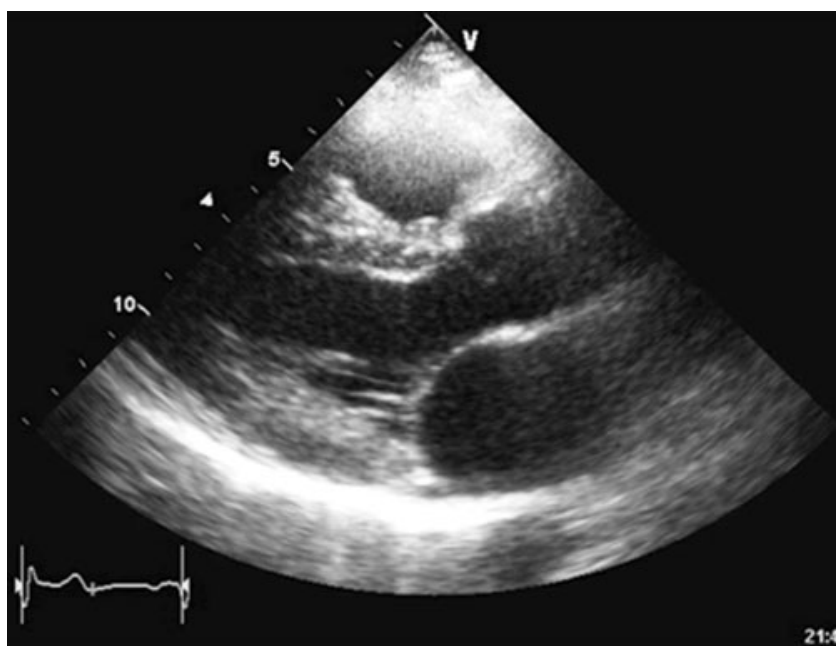

Fig. 3 Transthoracic echocardiogram with return of normal systolic function after initiating medical treatment

\section{Conclusion}

Excessive thyroid hormone production can result in severe transient left ventricular dysfunction. Hyperthyroid patients can present with angina symptoms and abnormal ECGs in the absence of coronary artery disease. A myocardial infarction can be induced due to increased demand [4]. A hypertrophic heart due to an increase in cardiac protein synthesis is also seen [5]. Forfar et al. [6] discovered that hyperthyroid patients have an elevated ejection fraction at rest but experience significant declines during exercise, also known as hyperthyroid cardiomyopathy [1]. We postulate that our patient has been in a thyrotoxicosis state for several months. We speculate that a surge of catecholamine release during physical stress in combination with a reduced ejection fraction caused by the thyrotoxicosis state resulted in severe left ventricular dysfunction. After initialising medical treatment the symptoms were reduced and the left ventricular function returned to normal with borderline left ventricular hypertrophy remaining. In this case report we demonstrate a combination of reversible cardiomyopathy related to stress (Tako Tsubo) and thyrotoxicosis that resolved completely with medical treatment.

Open Access This article is distributed under the terms of the Creative Commons Attribution Noncommercial License which permits any noncommercial use, distribution, and reproduction in any medium, provided the original author(s) and source are credited.

\section{References}

1. Cini G, Carpi A, Mechanick J, et al. Thyroid hormones and the cardiovascular system: pathophysiology and interventions. Biomed Pharmacother. 2009;63:742-53.

2. Walker JD, Crawford Jr RA, Mukherjee R, et al. The direct effects of $3,5,3^{\prime}$ triiodo-L-thyronine (T3) on myocyte contractile processes. Insights into mechanisms of action. J Thorac Cardiovasc Surg. 1995;110:1369-79.

3. Lyon AR, Rees PSC, Prasad S, et al. Stress (TakoTsubo) cardiomyopathy - a novel pathophysiological hypothesis to explain catecholamine induced acute myocardial stunning. Nat Clin Pract. 2008;5(1):22-9.

4. Froeschl M, Haddad H, Commons AS, et al. Thyrotoxicosis-an uncommon cause of heart failure. Cardiovas Pathol. 2005;14:24-7.

5. Ojamaa K, Samarel A, Kupfer T, et al. Thyroid hormone effects on cardiac gene expression independent of cardiac growth and protein synthesis. Am J Physiol. 1992;263:E534-40.

6. Forfar JC, Muir AL, Sawers SA, et al. Abnormal left ventricular function in hyperthyroidism: evidence for a possible reversible cardiomyopathy. N Engl J Med. 1982;307:1165-70. 